\title{
PROJECT-BASED SUPPLY CHAIN COOPERATIVE INCENTIVE BASED ON RECIPROCITY PREFERENCE
}

\author{
$\mathrm{Wu}, \mathrm{G} .-\mathrm{D}$. \\ Jiangxi University of Finance and Economics, Nanchang, Jiangxi, China \\ E-Mail: gd198410@126.com
}

\begin{abstract}
Within project-based supply chain inter-organizational cooperative innovation, the achievement of project value-adding reflects by factors such as effect level of project-based organizations, the relationship between construction project cooperative innovation objectives. Therefore, based on the assumption of equal cooperation between project-based organizations, considering the relationship of effect cost between knowledge input and innovation stage, and the reciprocity preference of projectbased organizations, the collaborative incentive model for project-based supply chain cooperative innovation was established, and the digital simulation was presented. The results show that, the project-based supply chain cross-organizational cooperative innovation is in the most favourable position to be realized when rising project-based organizations' effort level at one stage can reduce the effort cost of another stage. The reciprocity preference of project-based organization does not automatically lead to the achievement of the project-based supply chain cross-organizational cooperative innovation, but can enhance the incentive outcome of project value-adding sharing and knowledge collaboration.

(Received, processed and accepted by the Chinese Representative Office.)
\end{abstract}

Key Words: Project-Based Supply Chain, Reciprocity Preference, Cooperative Innovation

\section{INTRODUCTION}

Construction is an information and knowledge driven industry. Construction firms all over the world are increasingly being challenged by high-cost pressure, shortened project cycles and increasing competition. Within a business environment where fast and reliable access to knowledge is a key success factor, the efficient handling of organizational knowledge is crucial [1]. Cooperation is necessary for rapid knowledge acquirement since the cooperation among project-based organizations lays the foundation of knowledge innovation. In regard to project-based supply chain cross-organizational cooperative innovation, once the cooperation relationship between project-based organizations is established, it will not change throughout project construction [2]. Project-based organizations incline to counteract each other's efforts because common deviations appear easily due to the difficulty of measuring project benefit and it is not easy to realize project-based supply chain cross-organizational cooperative innovation owing to the large number of project-based organizations involving in cooperative innovation [3-4]. Because of projects' uncertainty and temporality, project-based organizations tend to present frequentation, dynamics and complexity, causing higher risk of immoral behaviour conducted by both partners. The construction industry is characterized with high fragmentation, low productivity, cost and time overruns, and conflicts and disputes compared with other manufacturing industries [5]. By considering one specific objective of the project and the effect of project-based organizations' behavioural preference on that objective, the coming behaviour of project-based organizations can be judged effectively and measures can be adopted accordingly [6].

Therefore, this paper introduces the concept of reciprocity preference that means projectbased organizations would exhibit motivation for fairness and reciprocity, thus considering others' benefit when pursuing their own benefit [7]. Unlike the concepts of cooperation and 
revenge in repeated games, organizations of reciprocity preference respond to friendly or antagonistic behaviour even though no expected benefit exists [8], which has been proved by Social Exchange Theory and experimental results of Behavioural Economics [9-11]. Up to now, the concept of reciprocity preference has been introduced to and discussed in Principalagent Theory Model [12-13], in supply of public goods [14], in supply chain cooperation [15], in staff management [16] and so forth. However, most literature analysed the influence of reciprocity preference on agents' choice of behaviour through empirical study [17-18], which is short of rigorous model deduction and quantitative analysis, making it hard to put forward practical strategies and measures to the point. To compensate for that deficiency, this paper introduces reciprocity preference into project-based supply chain cross-organizational cooperative innovation with the assumption that project-based supply chain crossorganizational cooperative innovation mainly involves knowledge input, which can be offered by project-based organizations independently and knowledge innovation, which necessitates cooperative efforts from all project-based organizations involved [19]. The alternative relationship between the effort cost of knowledge input and that of knowledge innovation is also taken into account since constraints like resources available exist. Through comprehensive analysis of the influence of reciprocity preference on project-based organizations' choice of behaviour, output level and motivation effect, this paper is hopeful of providing theoretical instruction and support for policy-making.

\section{MODEL DESCRIPTION}

Project-based supply chain cross-organizational cooperative innovation is actually the interplay among project-based organizations, the core of which is the cross-organizational flow and transmission of knowledge, laying the foundation for the achievement of crossorganizational interplay, cooperative innovation and project value-adding [20]. Project-based supply chains, consisting of a series of project-based organizations including owners, designers, supervisors, and builders, take on typical project-centred cross-organizational structure with project value-adding being the profit source of supply chains and the benefit origin of project-based organizations. Here, some presumptions concerning the achievement of project value-adding are made as following:

(1) Within project-based supply chain cross-organizational cooperative innovation, owners, as dominant organizations, hold absolute power of control and leading, and only take charge of designing supply chains' motivation mechanism which guides the behaviour of project-based organizations such as contractors and designers. It is also presumed that all project-based organizations are reasonable economical bodies that are risk neutral and seek maximization of self-interests.

(2) Project-based supply chain cross-organizational cooperative innovation comprises knowledge input and knowledge innovation, both of which are conducted by all project-based organizations. Knowledge input can be done by any single organization while knowledge innovation that meets the knowledge need of projects must be completed together by all project-based organizations. Consequently, one organization's effort level does not affect others' effort level at knowledge input stage but does at knowledge innovation stage. Here we suppose the effort level of the $i^{\text {th }}$ project-based organization at knowledge input stage is $a_{i}$, and the innovation effort made by the $i^{\text {th }}$ project-based organization for the $j^{\text {th }}$ is $b_{i j}$, where $a_{i}$, $b_{i j} \geq 0$;

(3) The effort cost $C\left(a_{i}, b_{i}\right)$ of project-based organizations is a strictly monotonically increasing function of effort level $a_{i}$ and $b_{i}$ [21]:

$$
C\left(a_{i}, b_{i}\right)=\frac{1}{2} \eta\left(a_{i}^{2}+2 k a_{i} b_{i}+b_{i}^{2}\right)
$$


where $\eta$ is the effort cost coefficient of cooperative innovation among project-based organizations with $\eta>0 ; k,-1<k<1$ is the marginal cost rate of substitution of effort level at knowledge input stage for that at knowledge innovation stage, i.e. the impact of unit change of effort level at one stage on the effort cost at the other stage. $b_{i}=\sum_{j=1, j \neq i}^{N} b_{i j}$ denotes the total level of effort made by the $i^{\text {th }}$ project-based organization for the other $N-1$ organizations.

(4) $\pi_{i}$, the output of $i^{\text {th }}$ project-based organization is influenced by its own knowledge input effort and knowledge innovation effort of the other organizations, which can be expressed as following [22]:

$$
\pi_{i}=\tau a_{i}+(1-\tau) \sum_{j=1, j \neq i}^{N} b_{j i}+\gamma a_{i} \sum_{j=1, j \neq i}^{N} b_{j i}+\varepsilon_{i}
$$

where $\tau$ and $1-\tau$ indicate the influence coefficients on the $i^{\text {th }}$ project-based organization's output of the knowledge input effort made by that organization and the knowledge innovation effort made by the other organizations. Since project-based organizations possess various core knowledge, their potential capability level at knowledge innovation stage differs under different division of responsibility, which is reflected in $\tau$ and $1-\tau$. Besides, the fact that knowledge demanded on designing, building, checking and accepting at concept stage, construction stage and completion stage respectively are diverse within different projects leads to varied knowledge input level for which designers, contractors, and supervisors strive throughout projects' life cycles, thus affecting the effort level of project-based organizations at knowledge innovation stage. Furthermore, owing to the fact that project-based organizations' effort making at knowledge input and knowledge innovation stages require the same knowledge, skills and experience of project-based organizations, the increase of effort level at one stage will inevitably lead to changes of the effort level at the other stage if project-based organizations' available resources are constrained. Taking into account of the concept of reciprocity preference, it is natural that project-based organizations would adjust their knowledge innovation effort level according to others'. Assuming $0 \leq \tau \leq 1$, then $\tau=0$ indicates great reliance of the $i^{\text {th }}$ organization's effort level on others' and strong cooperative will among organizations while $\tau=1$ denotes in the other way round except that the collaborative effect of project-based organizations $\gamma$, which is actually the influence coefficient of the $i^{\text {th }}$ project-based organization on its own output given the collaboration between its knowledge input and other organizations' knowledge innovation, on their output is marked. In project-based supply chain cross-organizational cooperative innovation, when the knowledge input made by the $i^{\text {th }}$ organization is combined with other organizations' innovative knowledge and bring out new knowledge needed by the projects, project-based organizations' skill innovation ability will be enhanced and new benefit can be earned. Here we suppose $0 \leq \gamma<1$ with $\gamma=0$ denoting no effect of project-based organizations' knowledge collaboration on their output.

(5) The value-adding of project-based supply chain is decided by the total output of all project-based organizations [23]. Supposing project-based organizations' output is additive, we have:

$$
\Pi=\sum_{i=1}^{N} \pi_{i}
$$

(6) Owners adopt the incentive mechanism of fixed-price lump-sum plus royalty contract as Eq. (4) shows, which means project-based organizations' benefit comprises of regular fee $\varpi_{i}$ offered by owners and the share of project value-adding $\beta_{i} \Pi$. To simplify model analysis, we assume unique project value-adding share coefficient $\beta$ for all project-based organizations. Since owners who design the incentive mechanism for supply chains take out a fraction of project value-adding, we get $0 \leq N \beta<1$. 


$$
s=\varpi_{i}+\beta_{i} \Pi
$$

According to the assumptions above, the expected revenue of owners can be expressed as below:

$$
U_{o}=\left(1-\sum_{i=1}^{N} \beta_{i}\right) \Pi=(1-N \beta) \Pi=(1-N \beta) \sum_{i=1}^{N} \pi_{i}
$$

The expected revenue of the $i^{\text {th }}$ project-based organization is shown as followed:

$$
U_{i}=\beta \Pi-\frac{1}{2} \eta\left(a_{i}^{2}+2 k a_{i} b_{i}+b_{i}^{2}\right)
$$

As the designers of supply chains' incentive mechanism, owners are desired to maximize their utility function. Given information asymmetry, the knowledge input-innovation collaborative incentive problems under project-based supply chains are specified by $a_{i}, b_{i}, \beta$ and $k$.

$$
\begin{aligned}
& \max _{a_{i}>b_{i}>k \backslash k}(1-N \beta) \sum_{i=1}^{N} \pi_{i} \\
& \text { s.t. } U_{i} \geq \varpi_{i} \\
& \quad a_{i} 、 b_{i} 、 \beta 、 k \in \arg \max U_{i}
\end{aligned}
$$

\section{MODEL SOLUTION}

\subsection{Solution without reciprocity preference}

If reciprocity preference does not exist, $b_{i j}$ and $b_{j i}$ are independent on each other. Then, the first order condition for project-based supply cross-organizational innovation is as following:

$$
\frac{\partial U_{i}}{\partial a_{i}}=0, \quad \frac{\partial U_{i}}{\partial b_{i}}=0
$$

So we have:

$$
\left\{\begin{array}{l}
\beta\left(\tau+\gamma \sum_{j=1, i \neq j}^{N} b_{j i}\right)-\eta\left(a_{i}+k b_{i}\right)=0 \\
b_{i}=0
\end{array}\right.
$$

Since all project-based organizations are rationality, we get: $\sum_{j=1, i \neq j}^{N} b_{j i}=0$.

Then, the Eq. above can be solved as below:

$$
a_{i 0}^{*}=\frac{\beta \tau}{\eta}, \quad b_{i 0}^{*}=0
$$

It is obvious that without reciprocity preference, no cooperation of knowledge innovation among project-based organizations happens, making it impossible to fulfil project-based supply chain cross-organizational cooperative innovation. Under this scenario, too much attention to knowledge input and the neglect of knowledge innovation make it hard to transform knowledge input to new knowledge projects need. It is also found that projectbased organizations' knowledge input effort level shows positive relation with project valueadding share coefficient $\beta$ and influence coefficient $\tau$, but negative relation with effort cost coefficient $\eta$.

\subsection{Solution with reciprocity preference}

If reciprocity preference exists, $b_{i j}$ is linear with $b_{j i}$, i.e. $b_{i j}=\delta b_{j i}$ [22]. Then:

$$
\delta \sum_{j=1, i \neq j}^{N} b_{j i}=b_{i},
$$


where $\delta$ is the reciprocity preference extent of project-based organizations.

Substitute $\sum_{i=1, i \neq j}^{N} b_{j i}=\frac{1}{\delta} b_{i}$ to Eq. (6) and combine Eq. (8), we will get the Eq. (10):

$$
\left\{\begin{array}{l}
a_{i}=\frac{\beta \tau \eta \delta^{2}+\beta^{2} \gamma(1-\tau)-\beta(1-\tau) \eta k \delta}{\eta^{2} \delta^{2}-(\beta \gamma-\eta k \delta)^{2}} \\
b_{i}=\frac{\beta^{2} \gamma \tau+\beta \eta \delta-\beta \tau \eta \delta(1+k)}{\eta^{2} \delta^{2}-(\beta \gamma-\eta k \delta)^{2}}
\end{array}\right.
$$

Denote $A=\frac{\partial^{2} U_{i}}{\partial\left(a_{i}\right)^{2}}, \quad B=\frac{\partial^{2} U_{i}}{\partial a_{i} b_{i}}, \quad C=\frac{\partial^{2} U}{\partial\left(b_{i}\right)^{2}}$, we will come to the second order condition for project-based supply chain cross-organizational cooperative innovation as below:

$$
B^{2}-A C<0, A C<0 \text { or } B^{2}-A C<0, A<0
$$

Since

we get

$$
A=\frac{\partial^{2} U_{i}}{\partial\left(a_{i}\right)^{2}}=-\eta, B=\frac{\partial^{2} U_{i}}{\partial a_{i} b_{i}}=\frac{\beta \gamma}{\delta}-\eta k, C=\frac{\partial^{2} U}{\partial\left(b_{i}\right)^{2}}=-\eta
$$

$$
B^{2}-A C=\frac{(\beta \gamma-\eta k \delta)^{2}-\eta^{2} \delta^{2}}{\delta^{2}}<0
$$

According to the maximum value property of binary function, Eq. (12) must be satisfied in order to for $U_{i}$ to get maximum value at $\left(a_{i}, b_{i}\right)$.

$$
\eta^{2} \delta^{2}-(\beta \gamma-\eta k \delta)^{2}>0
$$

So, the optimal effort level of project-based organizations at knowledge input and knowledge innovation stage is expressed by Eq. (13):

$$
\left\{\begin{array}{l}
a_{i}^{*}=\frac{\beta \tau \eta \delta^{2}+\beta(1-\tau)(\beta \gamma-\eta k \delta)}{\eta^{2} \delta^{2}-(\beta \gamma-\eta k \delta)^{2}} \\
b_{i}^{*}=\frac{\beta \tau(\beta \gamma-\eta k \delta)+\beta \eta \delta(1-\tau)}{\eta^{2} \delta^{2}-(\beta \gamma-\eta k \delta)^{2}}
\end{array}\right.
$$

\section{ANALYSIS AND CONCLUSIONS}

Conclusion 1. Only if $\frac{\beta \gamma}{\eta(1+k)}<\delta<\frac{\beta \gamma}{\eta|k|}$ project-based organizations will choose to implement knowledge innovation and will it be favourable for achieving project-based supply chain cross-organizational cooperative innovation.

Eq. (12) tells us if $\frac{\beta \gamma}{\eta(1+k)}<\delta<\frac{\beta \gamma}{\eta|k|}, b_{i}^{*}$ will be greater than 0 , i.e. greater than the projectbased organizations' effort level at knowledge innovation stage without reciprocity preference $b_{i 0}^{*}=0$. If $\delta<\frac{\beta \gamma}{\eta(1+k)}$, then $b_{i}^{*}<0$ and $b_{i}^{*} \leq 0$, meaning that project-based organizations'

knowledge innovation effort level is 0 . Therefore, reciprocity preference does not necessarily raise project-based organizations' knowledge innovation effort, nor does it certainly contribute to realize project-based supply chain cross-organizational cooperative innovation. The fact is only if the extent of reciprocity of preference falls in a certain range will it be favourable for project-based organizations to expand knowledge input, making it possible to achieve project-based supply chain cross-organizational cooperative innovation.

Inference 1. When the increase of effort level at knowledge innovation adds project-based organizations' effort cost at knowledge input stage, project-based organizations' effort level at 
knowledge input stage can be raised even with relatively low reciprocity preference, which provides the best condition for project-based supply chain cross-organizational cooperative innovation. When $\beta, \gamma$ and $\eta$ are fixed, if $k$ increases, $\delta$ will decrease and so will the extent of project-based organizations' reciprocity preference. If $0<k<1$, increasing project-based organizations' effort level at knowledge innovation stage will add their effort cost at knowledge input stage. If $-1<k<0$, vice versa.

Conclusion 2. If $\frac{\beta \gamma}{\eta(1+k)}<\delta<\frac{\beta \gamma}{\eta|k|}$, reciprocity preference will raise project-based organizations' effort level at knowledge input stage, showing that reciprocity preference promotes reciprocal behaviour among project-based organizations, the socialization and internalization of knowledge, and project-based organizations' innovation ability, which validates the conclusions made by Zhang et al. [17].

Comparing Eq. (9) with Eq. (13), we have:

$$
a_{i}^{*}=\frac{\beta \tau \eta \delta^{2}+\beta(1-\tau)(\beta \gamma-\eta k \delta)}{\eta^{2} \delta^{2}-(\beta \gamma-\eta k \delta)^{2}}>\frac{\beta \tau \eta \delta^{2}}{\eta^{2} \delta^{2}-(\beta \gamma-\eta k \delta)^{2}}>\frac{\beta \tau \eta \delta^{2}}{\eta^{2} \delta^{2}}=\frac{\beta \tau}{\eta}=a_{i 0}^{*}
$$

Inference 2. According to Conclusion 1 and 2, reciprocity preference is to raise project-based organizations' effort level of knowledge input-innovation if $\frac{\beta \gamma}{\eta(1+k)}<\delta<\frac{\beta \gamma}{\eta|k|}$, and project value-

adding can be achieved better with knowledge collaboration. Besides, project value-adding share coefficient $\beta$, knowledge collaboration coefficient $\gamma$, and effort cost coefficient $\eta$ hold impacts on project-based organizations' effort level of knowledge input-innovation, too. Given a fixed reciprocity preference, none of increase of $\beta$ or $\gamma$, or decrease of $\eta$ contributes to fulfil project-based supply chain cross-organizational cooperative innovation, because projectbased organizations are able to acquire high benefit with low effort under high $\beta, \gamma$ or low $\eta$, hurting their initiative to raising effort level in knowledge input-innovation.

Inference 3. The more project-based organizations involved the more favourable for project value-adding fulfilling. Because reciprocity preference provides positive incentive to crossorganizational knowledge transmission and organization learning that boost advancement of project-based organizations' core capability and improve project operation performance [24], organizations are ready to enhance their effort level in knowledge input-innovation even with low reciprocity preference.

From the $6^{\text {th }}$ assumption, we get $0 \leq \beta<\frac{1}{N}$ where $\beta$ and reciprocity preference $\delta$ converges

to 0 when $N$ comes near $+\infty$ and other parameters stay unchanged. Under this scenario, low reciprocity will raise project-based organizations' knowledge input-innovation effort level as stated by Inference 2. Therefore, the characteristic of large and wide engagement in construction projects definitely serves as a promising solution for construction project cooperation.

Conclusion 3. If $\frac{\beta \gamma}{\eta(1+k)}<\delta<\frac{\beta \gamma}{\eta|k|}$, reciprocity preference is negatively related with project-based organizations' effort level, i.e. the higher reciprocity preference, the lower knowledge inputinnovation effort level. This can be explained by the fact that project-based organizations can obtain relatively high revenue by low knowledge effort with high reciprocity preference that is assumed to be the same among all project-based organizations here. 


$$
\left\{\begin{array}{l}
\frac{\partial a_{i}^{*}}{\partial \delta}=-\frac{\beta \eta(\beta \gamma-\eta k \delta)^{2}[(1-\tau) k+2 \tau \delta]+\beta k \eta^{2} \delta^{2}[(1-\tau) \eta+2 \tau]+2 \beta(1-\tau) \eta^{2} \delta(\beta \gamma-\eta k \delta)}{\left[\eta^{2} \delta^{2}-(\beta \gamma-\eta k \delta)^{2}\right]^{2}}<0 \\
\frac{\partial b_{i}^{*}}{\partial \delta}=-\frac{\beta \eta^{3} \delta^{2}+\beta^{2} \eta \gamma(1-\tau)(\beta \gamma-\eta k \delta)+2 \beta^{2} \eta^{2} \gamma \tau \delta+\beta \tau \eta^{3} \delta^{2}(1+k)}{\left[\eta^{2} \delta^{2}-(\beta \gamma-\eta k \delta)^{2}\right]^{2}}<0
\end{array}\right.
$$

Conclusion 4. With $\frac{\beta \gamma}{\eta(1+k)}<\delta<\frac{\beta \gamma}{\eta|k|}$, the bigger the project value-adding share coefficient $\beta$, the higher project-based organizations' knowledge input-innovation effort level and the more favourable for project-based supply chain cross-organizational cooperative innovation.

In regard to $a_{i}^{*}=\frac{\beta \tau \eta \delta^{2}+\beta(1-\tau)(\beta \gamma-\eta k \delta)}{\eta^{2} \delta^{2}-(\beta \gamma-\eta k \delta)^{2}}$, the increase of $\beta$ leads to bigger $\beta \tau \eta \delta^{2}+\beta(1-\tau)(\beta \gamma-\eta k \delta)$ and $(\beta \gamma-\eta k \delta)^{2}$ but smaller $\eta^{2} \delta^{2}-(\beta \gamma-\eta k \delta)^{2}$, which combined effect is bigger $a_{i}^{*}$. The same rule is for $b_{i}^{*}=\frac{\beta^{2} \gamma \tau+\beta \eta \delta[1-\tau(1+k)]}{\eta^{2} \delta^{2}-(\beta \gamma-\eta k \delta)^{2}}$.

Conclusion 5. With $\frac{\beta \gamma}{\eta(1+k)}<\delta<\frac{\beta \gamma}{\eta|k|}$, the bigger the project-based organizations' knowledge collaboration coefficient $\gamma$, the higher project-based organizations' knowledge inputinnovation effort level because bigger $\gamma$ brings higher skill innovation ability and more project value-adding, for which project-based organizations are willing to raise their knowledge input-innovation effort.

In regard to $a_{i}^{*}=\frac{\beta \tau \eta \delta^{2}+\beta(1-\tau)(\beta \gamma-\eta k \delta)}{\eta^{2} \delta^{2}-(\beta \gamma-\eta k \delta)^{2}}$, the increase of $\gamma$ leads to bigger $\beta \tau \eta \delta^{2}+\beta(1-\tau)(\beta \gamma-\eta k \delta)$ and $(\beta \gamma-\eta k \delta)^{2}$ but smaller $\eta^{2} \delta^{2}-(\beta \gamma-\eta k \delta)^{2}$, which combined effect is bigger $a_{i}{ }^{*}$. The same rule is for $b_{i}^{*}=\frac{\beta^{2} \gamma \tau+\beta \eta \delta[1-\tau(1+k)]}{\eta^{2} \delta^{2}-(\beta \gamma-\eta k \delta)^{2}}$.

Inference 4. With reciprocity preference, project value-adding share shows stronger incentive to project-based organizations' effort input than without reciprocity preference. Besides, the promotional effect of $\beta$ on project-based organizations' effort input increases with $\delta$ and $\gamma$ going up.

Conclusion 6. The effect of reciprocity preference on project-based organizations' output is influenced by reciprocity preference extent $\delta$, project value-adding share coefficient $\beta$, knowledge collaboration coefficient $\gamma$, the influence coefficient of knowledge input effort on output $\tau$, and the marginal cost rate of substitution of knowledge input effort to knowledge innovation effort $k$.

Without reciprocity preference, the output of the $i^{\text {th }}$ project-based organization is $\pi_{i 0}^{*}$ :

$$
\pi_{i 0}^{*}=\tau a_{i 0}^{*}=\frac{\beta \tau^{2}}{\eta}
$$

With reciprocity preference, the output of the $i^{\text {th }}$ project-based organization is $\pi_{i}^{*}$ :

$$
\pi_{i}^{*}=\tau a_{i}^{*}+(1-\tau) \frac{b_{i}^{*}}{\delta}+\gamma a_{i}^{*} \frac{b_{i}^{*}}{\delta}
$$

According to Conclusion 2, we get:

$$
\left\{\begin{array}{rr}
\pi_{i}^{*}>\pi_{i 0}^{*} & \frac{\beta \gamma}{\eta(1+k)}<\delta<\frac{\beta \gamma}{\eta|k|} \\
\pi_{i}^{*}<\pi_{i 0}^{*} & 0<\delta<\frac{\beta \gamma}{\eta(1+k)} \sqrt{\frac{\beta \gamma \tau}{2 \beta \gamma \tau+\eta(1-\tau)}} \\
\pi_{i}^{*}>\pi_{i 0}^{*} & \frac{\beta \gamma}{\eta(1+k)} \sqrt{\frac{\beta \gamma \tau}{2 \beta \gamma \tau+\eta(1-\tau)}} \leq \delta<\frac{\beta \gamma}{\eta(1+k)}
\end{array}\right.
$$


From the Eq. above, it is obvious that only if $\delta \geq \frac{\beta \gamma}{\eta(1+k)} \sqrt{\frac{\beta \gamma \tau}{2 \beta \gamma \tau+\eta(1-\tau)}}$, the reciprocity preference will promote project-based organizations' output. Otherwise, it will even reduce output in turn.

Inference 5. According to the $3^{\text {rd }}$ assumption and Conclusion 6, if $\frac{\beta \gamma}{\eta(1+k)} \sqrt{\frac{\beta \gamma \tau}{2 \beta \gamma \tau+\eta(1-\tau)}} \leq \delta<\frac{\beta \gamma}{\eta(1+k)}$, reciprocity preference will advance project-based organizations' knowledge input-innovation effort level and thus increase project value-adding. Based on Conclusion 3 , if $\frac{\beta \gamma}{\eta(1+k)}<\delta<\frac{\beta \gamma}{\eta|k|}$,

reciprocity preference will lower project-based organizations' knowledge input-innovation effort level and thus reduce project value-adding. Hence, raising reciprocity preference is not amount to increasing project value-adding. When $\delta$ converges to $\frac{\beta \gamma}{\eta(1+k)}$, the project valueadding reaches its maximum.

\section{MODEL SIMULATION}

The fixed benefit for project-based organizations $\varpi_{i}$ has no impact on owners incentive effect on project-based organizations and their knowledge input-innovation effort level, so we assume $\varpi_{i}=0$. Based on model assumptions, we define detectable variable $a_{i}$ as the $i^{\text {th }}$ project-based organization' resources input level within project-based supply chain crossorganizational cooperative innovation, and $b_{i}$ as its communication level with other organizations. As to other parameters, we take $\eta=1$ and $\tau=0.5$.

(1) Relationship between project-based organizations' effort level and their reciprocity preference

Take $\beta=0.1$ and $\gamma=0.4$ and substitute related parameters in Eq. (13), we will get:

$$
\left\{\begin{array}{l}
a_{i}^{*}=\frac{0.05 \delta^{2}-0.05 k \delta+0.002}{\left(1-k^{2}\right) \delta^{2}+0.08 k \delta-0.0016} \\
b_{i}^{*}=\frac{0.05(1-k) \delta+0.002}{\left(1-k^{2}\right) \delta^{2}+0.08 k \delta-0.0016}
\end{array}\right.
$$

Let $k$ be $-0.5,0$, and 0.5 respectively, and the following figures will be obtained by Origin 8.5:

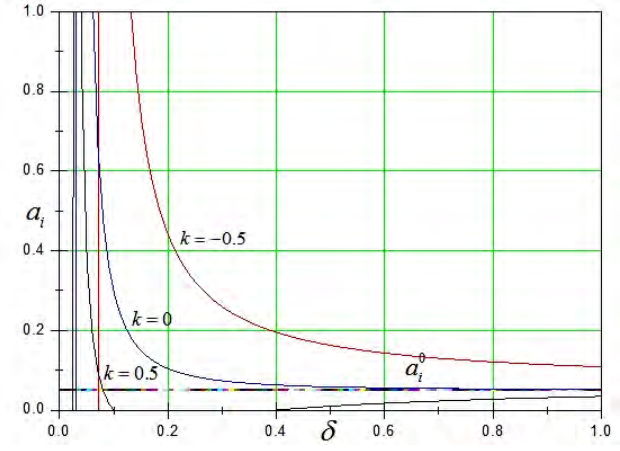

(a) Knowledge input effort level

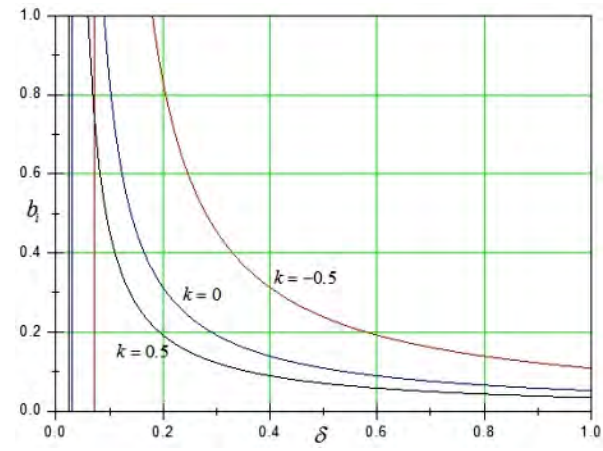

(b) Knowledge innovation effort level

Figure 1: Relationship between project-based organizations' effort level and their reciprocity preference with different $k$.

It can be found from Fig. 1 that raising reciprocity preference does not necessarily advance project-based organizations' knowledge input effort level no matter the linear relation 
between the effort cost of project-based organizations' knowledge input and knowledge innovation exists or not (Conclusion 1). Only if the extent of reciprocity of preference falls in a certain range will project-based organizations' knowledge input-innovation effort level decrease with higher reciprocity preference (Conclusion 3). On the other hand, project-based organizations' knowledge input-innovation effort level decreases if $k$ becomes bigger. When the linear relation between the effort cost of project-based organizations' knowledge input and knowledge innovation exists $(k<0)$, i.e. when the advancement of effort cost at one stage means cost decline at the other stage, project-based organizations' effort level reaches its highest. So, if the relation between the effort cost of project-based organizations' knowledge input and knowledge innovation is controllable, project-based organizations are more likely to keep it as cost substitutable. In actual project-based supply chain cross-organizational cooperative innovation, project-based organizations are willing to enhance knowledge innovation efforts to maximize project value-adding and their own shares, since knowledge decays when transmitting among all organizations and each organization can absorb part of others' knowledge only.

(2) Relationship between project-based organizations' effort level and project valueadding share coefficient

Take $\delta=0.4$ and $\gamma=0.4$ and substitute related parameters in Eq. (13), we will get:

$$
\left\{\begin{array}{l}
a_{i}^{*}=\frac{0.2 \beta^{2}+0.08 \beta-0.2 k \beta}{-0.16 \beta^{2}+0.32 k \beta-0.16 k^{2}+0.16} \\
b_{i}^{*}=\frac{0.2 \beta^{2}+0.2(1-k) \beta}{-0.16 \beta^{2}+0.32 k \beta-0.16 k^{2}+0.16}
\end{array}\right.
$$

Let $k$ be $-0.5,0$, and 0.5 respectively, and the following figures will be obtained by Origin 8.5:

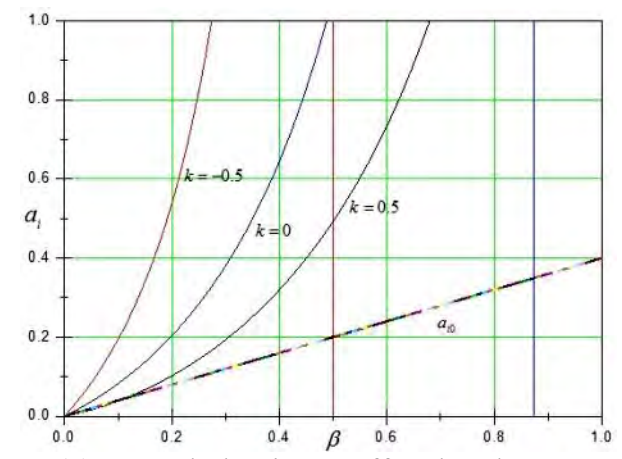

(a) Knowledge input effort level

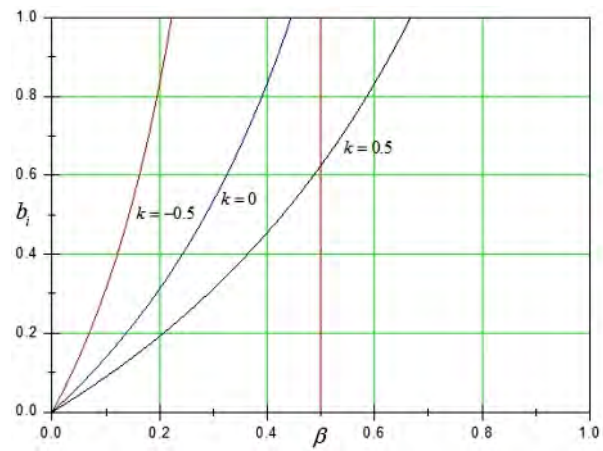

(b) Knowledge innovation effort level

Figure 2: Relationship between project-based organizations' effort level and project valueadding share coefficient with different $k$.

It is found from Fig. 2 that with $\frac{\beta \gamma}{\eta(1+k)}<\delta<\frac{\beta \gamma}{\eta|k|}$, the bigger the project value-adding share coefficient $\beta$, the higher project-based organizations' knowledge input-innovation effort level (Conclusion 4), no matter the linear relation between the effort cost of project-based organizations' knowledge input and knowledge innovation exists or not. The reciprocity preferences of all project-based organizations are set fixed $\delta=0.4$, so bigger $\beta$ does not necessarily lead to higher effort level (Inference 2). Take $k=0.5$ as an example. If $\beta>0.5$ the increase of $\beta$ does not raise project-based organizations' knowledge input level, since projectbased organizations are able to acquire high benefit with low effort, hurting their initiative to raising effort level in knowledge input-innovation. 
(3) Relationship between project-based organizations' effort level and knowledge collaboration coefficient

Take $\delta=0.4$ and $\beta=0.2$, substitute related parameters in Eq. (13), we will get:

$$
\left\{\begin{array}{l}
a_{i}{ }^{*}=\frac{0.02 \gamma+0.016-0.04 k}{0.16\left(1-k^{2}\right)-0.04 \gamma^{2}+0.16 k \gamma} \\
b_{i}^{*}=\frac{0.02 \gamma+0.04-0.04 k}{0.16\left(1-k^{2}\right)-0.04 \gamma^{2}+0.16 k \gamma}
\end{array}\right.
$$

Let $k$ be $-0.5,0$, and 0.5 respectively, and the following figures will be obtained by Origin 8.5:

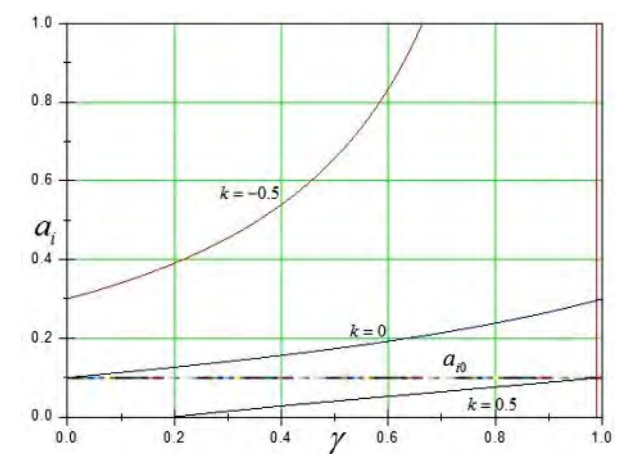

(a) Knowledge input effort level

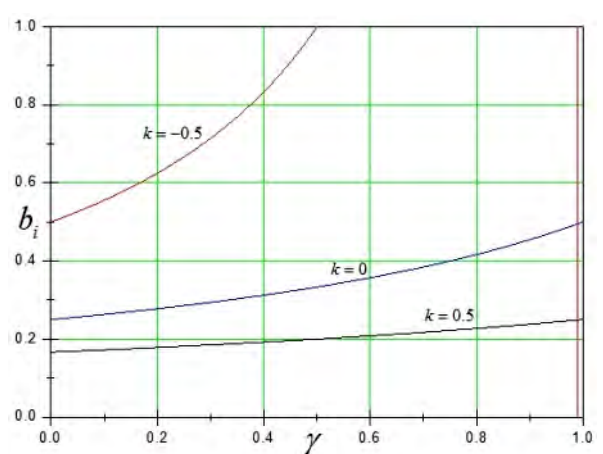

(b) Knowledge innovation effort level

Figure 3: Relationship between project-based organizations' effort level and knowledge collaboration coefficient with different $k$.

It can be seen in Fig. 3 that with $\frac{\beta \gamma}{\eta(1+k)}<\delta<\frac{\beta \gamma}{\eta|k|}$, bigger $\gamma$ makes higher project-based organizations' knowledge input-innovation effort level (Conclusion 5), no matter the linear relation between the effort cost of project-based organizations' knowledge input and knowledge innovation exists or not. Since the reciprocity preference of all project-based organizations are set fixed $\delta=0.4$, if $\frac{\beta \gamma}{\eta(1+k)}<\delta<\frac{\beta \gamma}{\eta|k|}$, the increase of $\beta$ does not necessarily

produce higher effort level (Inference 2). For example, when $k=-0.5$ and $\gamma>0.8$, the increase of $\beta$ does not raise project-based organizations' knowledge input effort level. In fact, if $k=-0.5$, $\delta$ will be greater than $\frac{\beta \gamma}{\eta(1+k)}$, making reciprocity preference fail to promote knowledge input $\left(a_{i}<a_{i 0}\right)$. In regard to project-based organizations' knowledge input-innovation effort level, when the advancement of effort cost at one stage means cost decline at the other stage $(-1<k<0)$, project-based organizations' effort level reaches its highest.

(4) Relationship between project-based organizations' output and reciprocity preference

Substitute Eq. (16) in Eq. (15), we will get $\pi_{i}$ as the function of $\delta$.

$$
\pi_{i}=\frac{0.025(2-k) \delta^{2}+0.5(0.002-0.05 k) \delta+0.01}{\left(1-k^{2}\right) \delta^{2}+0.08 k \delta-0.0016}+0.4 * \frac{0.05 \delta^{2}-0.05 k \delta+0.002}{\left(1-k^{2}\right) \delta^{2}+0.08 k \delta-0.0016} * \frac{0.05(1-k) \delta^{2}+0.002 \delta}{\left(1-k^{2}\right) \delta^{2}+0.08 k \delta-0.0016}
$$

Let $k$ be $-0.5,0$, and 0.5 respectively, and the following figures will be obtained by Origin 8.5 (see Fig. 4).

Fig. 4 shows clearly that when $\frac{\beta \gamma}{\eta(1+k)}<\delta<\frac{\beta \gamma}{\eta|k|}$, reciprocity preference will lower project-

based organizations' knowledge input-innovation effort level and thus reduce project valueadding, no matter the linear relation between the effort cost of project-based organizations' knowledge input and knowledge innovation exists or not. 


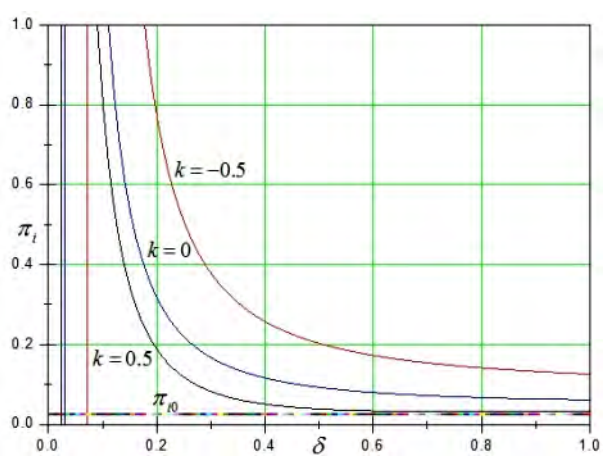

Figure 4: Relationship between project-based organizations' output and reciprocity preference with different $k$.

When $\delta$ converges to $0.08(k=-0.5), 0.04(k=0)$ and $0.027(k=0.5)$, project-based organizations' output and supply chains' value reach maximum. When $\delta$ is greater than $0.08(k$ $=-0.5), 0.04(k=0)$ and $0.027(k=0.5)$, project-based organizations' output will still be higher than that without reciprocity preference. Similar analysis can be applied to the all project-based supply chains.

(5) Relationship between project-based organizations' output and project value-adding share coefficient

Substitute Eq. (17) in Eq. (15), we will get $\pi_{i}$ as the function of $\beta$.

$$
\pi_{i}=\frac{0.35 \beta^{2}+0.29 \beta-0.35 k \beta}{-0.16 \beta^{2}+0.32 k \beta-0.16 k^{2}+0.16}+0.4 * \frac{0.2 \beta^{2}+0.08 \beta-0.2 k \beta}{-0.16 \beta^{2}+0.32 k \beta-0.16 k^{2}+0.16} * \frac{0.5 \beta^{2}+0.5 \beta-0.5 k \beta}{-0.16 \beta^{2}+0.32 k \beta-0.16 k^{2}+0.16}
$$

Let $k$ be $-0.5,0$, and 0.5 respectively, and the following figures will be obtained by Origin 8.5:

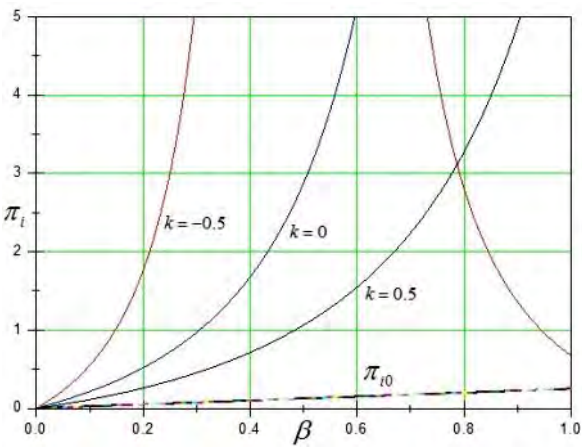

Figure 5: Relationship between project-based organizations' output and project value-adding share coefficient with different $k$.

We can see in Fig. 5 that with $\frac{\beta \gamma}{\eta(1+k)}<\delta<\frac{\beta \gamma}{\eta|k|}$, the bigger the project value-adding share coefficient $\beta$, the higher project-based organizations' knowledge input-innovation effort level, thus expanding project-based organizations' output, no matter the linear relation between the effort cost of project-based organizations' knowledge input and knowledge innovation exists or not. However, since the reciprocity preference of all project-based organizations are set fixed $\delta=0.4$, the increase of project value-adding share coefficient may not enhance projectbased organizations' effort level or improve their output if $\delta<\frac{\beta \gamma}{\eta(1+k)}$ (Inference 2). For example, if $k=-0.5$ and $\beta>0.5$, raising project value-adding share coefficient will actually lower project-based organizations' output. Therefore, when designing supply chain incentive 
mechanism within project-based supply chain cross-organizational cooperative innovation, owners should fully consider project-based organizations' reciprocity preference so as to avoid that too much project value-adding share lowers supply chains' value-adding.

(6) Relationship between project-based organizations' output and knowledge collaboration coefficient

Substitute Eq. (18) in Eq. (15), we will get $\pi_{i}$ as the function of $\gamma$.

$\pi_{i}=\frac{0.35 \beta^{2}+0.29 \beta-0.35 k \beta}{-0.16 \beta^{2}+0.32 k \beta-0.16 k^{2}+0.16}+0.4 * \frac{0.2 \beta^{2}+0.08 \beta-0.2 k \beta}{-0.16 \beta^{2}+0.32 k \beta-0.16 k^{2}+0.16} * \frac{0.5 \beta^{2}+0.5 \beta-0.5 k \beta}{-0.16 \beta^{2}+0.32 k \beta-0.16 k^{2}+0.16}$

Let $k$ be $-0.5,0$, and 0.5 respectively, and the following figures will be obtained by Origin 8.5:

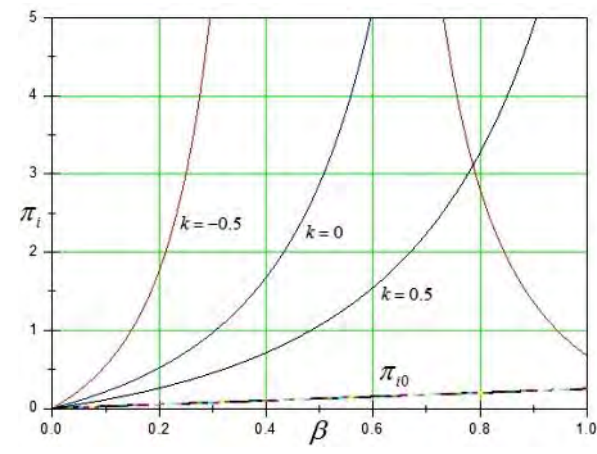

Figure 6: Relationship between project-based organizations' output and knowledge collaboration coefficient with different $k$.

It can be found in Fig. 6 that if $\frac{\beta \gamma}{\eta(1+k)}<\delta<\frac{\beta \gamma}{\eta|k|}$, raising knowledge collaboration coefficient makes higher project-based organizations' knowledge input-innovation effort level, and thus greater output, no matter the linear relation between the effort cost of project-based organizations' knowledge input and knowledge innovation exists or not. Also found is when the advancement of effort cost at one stage means cost decline at the other stage $(-1<k<0)$, project-based organizations' effort level reaches its highest. Besides, if $\frac{\beta \gamma}{\eta(1+k)}<\delta<\frac{\beta \gamma}{\eta|k|}$, projectbased organizations' output will be higher than that without reciprocity preference.

\section{CONCLUSIONS}

Assuming the existence of reciprocity preference among project-based organizations, this paper established the model of project-based supply chain cross-organizational cooperative innovation. By considering the effect of reciprocity preference, project value-adding share, knowledge collaboration, the linear relation between effort cost at different stages on projectbased organizations' behaviour and output, we obtained several conclusions and lessons that have been testified by model simulation.

(1) Project-based organizations' knowledge input-innovation effort level is greatly influenced by effort cost, knowledge collaboration coefficient, and project value-adding share coefficient as well as reciprocity preference. It should be noted that given fixed reciprocity preference, none of increase of project value-adding share coefficient or knowledge collaboration coefficient, or decrease of effort cost coefficient are necessarily to advance project-based organizations' effort level. However, if project-based organizations' effort level at both stages goes up and effort cost is lowered, the total project-based organizations' effort level is sure to increase. 
(2) Though reciprocity preference renders influence on project-based organizations' output, it cannot do better than without if not falling into a certain range. The substitution between the cost of knowledge input and knowledge innovation and only if the advancement of effort cost at one stage reduce cost at the other stage can project-based organizations' effort level reach its highest. Therefore, when designing supply chain incentive mechanism within project-based supply chain cross-organizational cooperative innovation, reciprocity preference and the linear relation between effort costs at different stage must be considered. In addition, given the large number of project-based organizations involved, information share platform and trust mechanism could be established within project-based supply chain crossorganizational cooperative innovation, in order to encourage reciprocal behaviour, raise project-based organizations' knowledge input-innovation effort level and achieve project value-adding.

(3) If reciprocity preference falls in a certain range, raising project value-adding share coefficient and knowledge collaboration coefficient will improve project-based organizations' knowledge input-innovation effort level and output level. But if reciprocity preference falls out of the range, the results will just be the opposite. Consequently, when designing supply chain incentive mechanism within project-based supply chain cross-organizational cooperative innovation, owners should not only try to raise project-based organizations' knowledge input-innovation effort level just by increasing project value-adding share coefficient or knowledge collaboration coefficient, but also consider to the full the extent of reciprocity preference, knowledge collaboration and the linear relation between effort cost at different stages so as to design more effective incentive mechanism based on maximizing project value-adding in a comprehensive view.

We believe the results of this paper provide theoretical and practical advice for strengthening project-based organizations' collaboration and cooperation and achieving project value-adding, making it easy for implementing project-based supply chain crossorganizational cooperative innovation. At the same time, we have seen some shortcomings of our work such as the assumption of fixed reciprocity preference. Further research should take deeper sight into the influence of varied reciprocity preference on project-based supply chain cross-organizational cooperative innovation.

\section{REFERENCES}

[1] Ribeiro, F. L. (2009). Enhancing knowledge management in construction firms, Construction Innovation: Information, Process, Management, Vol. 9, No. 3, 268-284, doi:10.1108/ 14714170910973493

[2] Chen, Y.; You, J. X. (2006). Qualitative simulation of engineering project collaboration performance in supply chain, China Civil Engineering Journal, Vol. 39, No. 2, 113-116

[3] Wei, G. X.; Yu, L. A.; Wang, S. Y. (2007). A study on incentive factors of team cooperation based on synergy effect, Systems Engineering - Theory \& Practice, Vol. 1, 1-9

[4] Liu, L.; Li, N. (2009). Study on improving profit allocation in virtual enterprises of construction project, China Civil Engineering Journal, Vol. 42, No. 1, 135-139

[5] Xue, X. L.; Wang, Y. W.; Shen, Q. P.; Yu, X. (2007). Coordination mechanism for construction supply chain management in the internet environment, International Journal of Project Management, Vol. 25, No. 2, 150-157, doi:10.1016/j.ijproman.2006.09.006

[6] Parrod, N.; Thierry, C.; Fargier, H.; Cavaille, J. B. (2007). Cooperative subcontracting relationship within a project supply chain: A simulation approach, Simulation Modelling Practice and Theory, Vol. 15, No. 2, 137-152, doi:10.1016/j.simpat.2006.09.016

[7] Liu, J. W.; Zhang, T. J.; Lin, Z. W. (2009). The empirical research of technique innovation capability of technique exploration team based on reciprocal enterprise environment, Studies in Science of Science, Vol. 27, No. 7, 1093-1100 
[8] Fehr, E.; Gachter, S. (2000). Fairness and retaliation: the economics of reciprocity, Journal of Economic Perspectives, Vol. 14, No. 3, 159-181, doi:10.1257/jep.14.3.159

[9] Brown, M.; Falk, A.; Fehr, E. (2004). Relational contracts and the nature of market interactions, Econometrica, Vol. 7, No. 3, 747-780, doi:10.1111/j.1468-0262.2004.00511.x

[10] Cropanzano, R.; Mitchell, M. S. (2005). Social exchange theory: an interdisciplinary review, Journal of Management, Vol. 31, No. 6, 874-900, doi:10.1177/0149206305279602

[11] Li, S. Y.; Wang, D. F.; Shi, Y. R. (2009). Studies on incentives of reciprocity: empirical evidence and implications, Journal of Industrial Engineering \& Engineering Management, Vol. 23, No. 2, $152-155$

[12] Tang, J. (2011). Analysis of the extended game model of reciprocity behavior based on social preference, Guangdong University of Business Studies, Vol. 26, No. 3, 12-16

[13] Sethi, R.; Somanathan, E. (2001). Preference evolution and reciprocity, Journal of Economic Theory, Vol. 97, No. 2, 273-297, doi:10.1006/jeth.2000.2683

[14] Tang, J.; Wang, Y. (2012). Public product supply theoretical model for uncertain stage under reciprocity behavior, Journal of Seeking, Vol. 1, 14-16

[15] Wang, X.; Chen, J. X. (2008). The evolutionary analysis of supply chain cooperative relationship between reciprocal and contract mechanisms, Operations Research and Management Science, Vol. 17, No. 5, 26-31

[16] Wan, D. F.; Luo, J. H.; Zhao, J. F. (2009). Managerial trustworthy behavior and employee's effect level: a two-stage sequential reciprocity game model, Systems Engineering, Vol. 27, No. 7, 101-106

[17] Zhang, T. J.; Pu, Y. J. (2010). The relativity among reciprocal preference, tacit knowledge transition and technology innovation capability - based on the data test of R\&D team, Management Review, Vol. 22, No. 10, 100-106

[18] Zhao, J.; You, J. X.; Zhang, T. J. (2011). Reciprocity-based knowledge conversion mechanism of knowledge-based enterprises, Journal of Tongji University (Natural Science), Vol. 29, No. 2, 303308

[19] Mohamed, S. F.; Anumba, C. J. (2006). Potential for improving site management practices through knowledge management, Construction Innovation: Information, Process, Management, Vol. 6, No. 4, 232-249, doi:10.1108/14714170610713917

[20] Shi, J. G.; Wu, G. D. (2011). Project-based supply chain cross-organizational cooperative innovation based on the perspective of knowledge flow, Science Research Management, Vol. 32, No. 12, 9-16

[21] Shi, J. G.; Wu, G. D.; Tang, D. Z. (2011). Project-based supply chain cross-organizational cooperative incentive mechanism based on knowledge flow, Soft Science, Vol. 25, No. 4, 44-49

[22] Kretschmer, T.; Puranam, P. (2008). Integration through incentives within differentiated organizations, Organization Science, Vol. 19, No. 6, 860-875, doi:10.1287/orsc.1070.0352

[23] Han, J. J.; Zhou, G. H.; Li, Y. L.; Cai, Y. (2012). A study on the cooperation behavioral of multiparticipates project team, Journal of Systems \& Management, Vol. 21, No. 1, 111-119

[24] Zhang, T. J. (2010). The research on the relativity among reciprocal preference, knowledge transfer and core competence cultivation, $R \& D$ Management, Vol. 22, No. 4, 47-52 